\title{
OS DIVERSOS TIPOS DE VIOLÊNCIA CONTRA A PESSOA IDOSA NOS ÂMBITOS FAMILIAR, SOCIAL E INSTITUCIONAL
}

Rafaela Parpinéli de Oliveira, Márcio França Teixeira

Universidade do Oeste Paulista - UNOESTE, curso de Direito, Presidente Prudente, SP. E-mail:

rafaceciliaoliveira@hotmail.com; mfrancateixeira@gmail.com

\section{RESUMO}

A violência contra a pessoa idosa integra uns dos maiores óbices para uma completa igualdade de direitos. Definida como um fenômeno social abrangente, ora difuso, ora muito concreto que consiste em preconceitos, maus tratos e abusos que se verificam nas fendas da lei (SECRETÁRIA DE DIREITOS HUMANOS DA PRESIDÊNCIA DA REPÚBLICA, 2014, p.07).

$O$ presente artigo tem como finalidade mostrar dados oriundos de pesquisas, assim como realizar comentários, críticas e possíveis soluções sobre o tema.

A elaboração do projeto seguirá o método dialético-dedutivo, com emprego de pesquisas à legislação e livros acerca da matéria objeto do tema exposto.

Trata-se de estudos que mostram as mudanças benéficas já conquistadas até o momento e também as dificuldades que são encontradas na realização das políticas voltadas a este grupo.

A conclusão obtida é que precisamos de mais efetividade nas políticas de prevenção e combate contra as violências que afligem essa parcela populacional.

Palavras-chave: Pessoa Idosa, Violência, Estatuto do Idoso, Necessidades, Leis.

\section{THE VARIOUS TYPES OF VIOLENCE AGAINST THE ELDERLY IN THE FAMILY, SOCIAL AND INSTITUTIONAL SITES}

\begin{abstract}
Violence against the elderly is one of the greatest obstacles to full equality of rights. Defined as a comprehensive social phenomenon, sometimes diffuse, sometimes very concrete, consisting of prejudices, mistreatment and abuse that occurs in the crevices of the law (SECRETARY OF HUMAN RIGHTS OF THE PRESIDENCY OF THE REPUBLIC, 2014).

The purpose of this article is to show data from researches, as well as to make comments, criticisms and possible solutions on the subject.

The elaboration of the project will follow the dialectic-deductive method, using researches to the legislation and books about the subject subject of the exposed subject.

These are studies that show the beneficial changes already achieved so far and also the difficulties that are found in the implementation of the policies directed to this group.

The conclusion obtained is that we need more effectiveness in the policies to prevent and combat violence that afflict this population.
\end{abstract}

Keywords: Elderly Person, Violence, Elderly Status, Needs, Laws.

\section{INTRODUÇÃO}

A pessoa idosa passou a fazer parte das pautas políticas globais recentemente. A Organização das Nações Unidas incluiu esse tema em seus tópicos apenas em 1956.

No Brasil, com o advento da Constituição Cidadã em 1988, incluiu-se os idosos no capítulo da seguridade social, ampliando a rede de proteção à pessoa idosa. Embora já existissem algumas 
políticas voltadas a este público, é notório que não havia o investimento necessário para uma mínima efetividade em, por exemplo, prevenções às violências existentes.

Posteriormente, nos anos de 1990, foi criada a Lei Orgânica da Assistência Social (Lei no 8.742), que passou a garantir o chamado "Beneficio de Prestação Continuada" (SECRETÁRIA DE DIREITOS HUMANOS DA PRESIDÊNCIA DA REPÚBLICA, 2014, p.12).

Ainda assim, não contávamos com uma legislação especificamente voltada à pessoa idosa. Foi em 2003, após sete anos de tramitação no Congresso Nacional que o Estatuto do Idoso foi enfim aprovado.

Mesmo atualmente, na vigência do citado Estatuto, inúmeros idosos sofrem violências diariamente e muitos deles sequer possuem conhecimento desses direitos e deveres que os assistem. É por este motivo que precisamos tomar conhecimento dos problemas que afligem essa parcela populacional, para então cumprirmos um de nossos deveres que vem descrito no artigo 230 da Constituição Federal (1998), qual seja:

A família, a sociedade e o Estado têm o dever de amparar as pessoas idosas, assegurando sua participação na comunidade, defendendo sua dignidade e bem-estar e garantindo-lhes o direito à vida.

Este artigo tem como objetivo mostrar que a velhice é um fenômeno heterogêneo e envelhecer na sociedade brasileira ainda é um risco, mesmo ponderando que este fenômeno é uma conquista vitoriosa da população, ela ainda possui um traço de insucesso (Paulo Roberto Barbosa Ramos, 2013). Por esta razão cabe uma discussão sobre o tema e possíveis soluções, considerando as reais necessidades da pessoa idosa, de modo que possam ter os seus direitos devidamente e efetivamente garantidos.

\section{METODOLOGIA}

O tipo de pesquisa a ser abordada é a bibliográfica, com consultas em livros, revistas e legislação vigente.

O procedimento para a coleta de dados bibliográficos contou com a seleção de leituras seletiva, crítica e analítica.

Houve visita à Delegacia do Idoso, onde obtive alguns dados com a assistente social Solange A. Morrone e o investigador de policia Rodney W. Luz, que também me emprestaram diversos livros para enriquecer o conteúdo relacionado ao tema exposto.

\section{RESULTADOS}

Entre os diversos livros analisados foi possível encontrar em comum o fato do crescimento da população nos últimos anos. No inicio do século XX, a esperança de vida não passava de 33.5 anos, chegando aos 50 na metade desse mesmo século.

Em 2011, a população idosa chegou a 23,5 milhões, número que estava previsto para ser alcançado em 2020 (SECRETÁRIA DE DIREITOS HUMANOS DA PRESIDÊNCIA DA REPÚBLICA, 2014, p.18).

No decorrer do estudo sobre o tema foi possível perceber que existem diversos tipos de violência, que são mais frequentes em famílias desfuncionais e que possuem em seu meio dependentes químicos e, que o próprio Estado faz parte dos agressores deste grupo populacional.

\section{DISCUSSÃO}

As violências contra a pessoa idosa podem ser classificadas como visíveis ou invisíveis: as primeiras são as lesões e mortes; as segundas por sua vez são aquelas que ocorrem sem machucar o corpo, mas provocam sofrimento, angústia, depressão e medo. E, infelizmente, essas últimas são 
praticamente incontáveis (MANUAL DE ENFRENTAMENTO À VIOLÊNCIA CONTRA A PESSOA IDOSA, 2014, p.37).

Maus-tratos contra este grupo foram expostos pela primeira vez em 1975, como "espancamento de avós" por dois pesquisadores ingleses Baker e Burston.

A violência contra a pessoa idosa pode assumir varias formas e ocorrer em diferentes situações. É impossível determiná-la em toda a sua dimensão.

O Estatuto do Idoso declara no capítulo IV, artigo 19, §1ㅇque:

Violência contra o idoso é qualquer ação ou omissão praticada em local publico ou privado que the cause morte, dano ou sofrimento físico ou psicológico.

Entendido os tipos de violências, passaremos a observar cada âmbito de ocorrência.

Paulo Roberto Barbosa Ramos (2013) observa que, a grande maioria da população idosa brasileira vive com suas famílias. E, infelizmente, é nesse espaço que são mais atingidos por meio de todas as formas de violência, que podem classificadas, de maneira resumida, em psicológica, financeira e física.

A família, não somente aqueles que são dependentes químicos, muitas vezes para manter seus vícios, manter padrões elevados de vida ou mesmo sustentar suas famílias, apossam-se dos proventos dos idosos e de seus bens, deixando-os em grandes atribulações.

Diante dos estudos foi possível perceber que mesmo diante dessas circunstâncias, as vítimas raramente denunciam aqueles que extorquem seus proventos. Isso ocorre em razão dos laços familiares e afetivos, devido ao receio que o idoso tem de prejudicar aquele familiar ou até mesmo o medo de sofrer conseqüências piores de outros familiares.

Recentemente, tivemos o desprazer de ver vinculado na mídia vídeos onde o filho adulto agredia a própria mãe acometida de Alzheimer (caso ocorrido na Região Metropolitana de São Luís no Maranhão). É ai que começamos a pensar em como a violência física faz parte do cotidiano de muitos idosos, principalmente dos que sofrem de alguma dependência física ou mental, decorrente do Alzheimer ou Parkinson, exemplificando.

Sobre as negligências, elas começam pelas que os serviços públicos praticam. Principalmente na área da saúde onde há o descuido e a inoperância dos órgãos de vigilância sanitária em relação aos abrigos e clinicas. Embora haja, atualmente, normas e padrões da Vigilância Sanitária, não há a fiscalização devida, permitindo que situações de violência institucional se instalem e se perduram (MANUAL DE ENFRENTAMENTO À VIOLÊNCIA CONTRA A PESSOA IDOSA, 2014, p.41).

Não é difícil perceber que temos problemas como inadequação das instalações, isolamento das pessoas idosas em seus aposentos, falta ou precariedade de assistência à sua saúde, dentre outras, quando lembramos a tragédia ocorrida no Rio de Janeiro, na Casa de Saúde Santa Genoveva em 1996, que acabou virando símbolo do concurso de vários tipos de negligencia que poderiam ter sido evitadas (Jornal O Globo, 1996).

Há ainda as negligencias que ocorrem diariamente no atendimento dos serviços de saúde, ou seja, as longas filas de espera para consultas e exames, que são marcados com intervalos de meses, a espera de anos por uma cirurgia enquanto o estado de saúde da pessoa idosa vai se agravando.

Essa violência estrutural reúne os aspectos oriundos da desigualdade social, do sofrimento provocado pela pobreza e pela miséria e das discriminações que os carentes de bens materiais mais sentem. É visível que nessa fase da vida, a falta de recursos materiais castiga muito mais.

A pobreza na velhice tende a agravar a dependência produzida por condições físicas e psicológicas. O liame entre dependência, pobreza e idade avançada adquire maior importância em 
relação à disseminação de recursos econômicos individuais e à disponibilidade de serviços voltados à sociedade.

Outro tipo de ausência do poder publico é o número insignificante de equipamentos públicos de apoio social às famílias das pessoas idosas. Os defeitos que as ILPI apresentam não podem servir de escusa para justificar o pequeno numero das existentes frente às necessidades deste grupo (MANUAL DE ENFRENTAMENTO À VIOLÊNCIA CONTRA A PESSOA IDOSA, 2014, p.63).

A violência institucional, que foi mostrada nas linhas acima, constitui uma grande parte das violências praticadas contra a pessoa idosa.

Então, é aí que nos fazemos à seguinte pergunta: O Estatuto do Idoso é uma lei eficaz? Sabemos que ele é uma lei válida, porém as pessoas sempre costumam dar um 'jeitinho' para burlar as preferências que o Estatuto traz. Estatuto esse que foi criado por uma necessidade apontada pela sociedade, que teve a precisão de implantar leis específicas a um grupo vulnerável.

Levando-se em consideração a questão posta acima, mostra-se as leis de proteção voltadas a este grupo social, algumas inovadoras, trazidas pela Lei no 10.741/03, que trouxe inferências em vários ramos do direito, inclusive o direito penal (Luiz Roberto Sales Souza e Christian Marcos Carboni, 2013).

O Estatuto considera idoso aquele com idade igual ou superior a sessenta anos. Se a pessoa idosa com esta idade completa vier a ser vítima de um homicídio culposo no dia subseqüente ao se tornar sexagenário, deverá ser aplicada a agravante do $\S 4$ 으, parte final, do artigo 121, do Código Penal. No entanto, se for lesionado no próprio dia de seu aniversário, indo a óbito no dia posterior, quando já era maior de sessenta anos, ao agente que praticou o crime não será aplicada a agravante, uma vez que de acordo com o artigo 4으, do Código Penal (Luiz Roberto Sales Souza e Christian Marcos Carboni):

Considera-se o tempo do crime o momento da ação ou omissão, ainda que outro seja o momento do resultado.

O Estatuto do Idoso em seus títulos VI e VII, também deu origem á catorze tipos penais ambicionando a tutela das pessoas idosas. Entre esses, alguns são verdadeiramente novos. São eles:

Art. 96 - Discriminar pessoa idosa, impedindo ou dificultando seu acesso a operações bancárias, aos meios de transporte, ao direito de contratar ou por qualquer outro meio ou instrumento necessário ao exercício da cidadania, por motivo de idade: Pena - Reclusão de 6 (seis) meses a 1 (um) ano e multa;

Art. 103 - Negar o acolhimento ou a permanência do idoso, como abrigado, por recusa deste em outorgar procuração à entidade de atendimento: Pena - detenção de 6 (seis) meses a 1 (um) ano e multa;

Art. 104 - Reter o cartão magnético de conta bancária relativa a benefícios, proventos ou pensão do idoso, bem como qualquer outro documento com objetivo de assegurar recebimento ou ressarcimento de dívida: Pena detenção de 6 (seis) meses a 2 (dois) anos e multa.

Há ainda outros tipos que foram criados pela Lei no 10.741/03, portanto vamos atentar para um ponto ainda mais polêmico, que é o artigo 94, que estabelece:

Aos crimes previstos nesta Lei, cuja pena máxima privativa de liberdade não ultrapasse 4 (quatro) anos, aplica-se o procedimento previsto na Lei $n^{\circ}$ 9.099, de 26 de setembro de 1995, e, subsidiariamente, no que couber, as disposições do Código Penal e do Código de Processo Penal.

O que quero mostrar com isso é que apesar de que nossas leis escritas para proteger esse grupo populacional podem ser comparadas às melhores do mundo, ainda temos autos índices de 
violências contra o mesmo. Portanto, o que temos que entender é que não necessitamos de mais resguardo legal. A nossa necessidade gritante é que a Constituição, os Estatutos e as Leis se efetivem, evitando assim que o Estado não se torne, também, um transgressor institucional.

\section{CONCLUSÃO}

A primeira conclusão é que uma sociedade para todas as idades não beneficia apenas as pessoas idosas, mas sim todas as gerações. As orientações prioritárias "de uma sociedade para todas as idades" devem levar a realizações concretas de ajuste, de tal forma que o sucesso de tal estratégia possa ser medido pelo progresso da qualidade de vida dos idosos.

Cabe aos governos cabe a incumbência principal de liderar as ações que promovam os direitos da pessoa idosa. Uma vez que faltam ações concretas do Estado para garantir os direitos conquistados (MANUAL DE ENFRENTAMENTO À VIOLÊNCIA CONTRA A PESSOA IDOSA, 2014, p.71).

-É preciso promover campanhas e movimentos de sensibilização da sociedade sobre as violências que mais acometem os idosos nessa etapa da vida, garantir que todas essas ações estejam associadas a mecanismos de coibição de abusos e maus-tratos;

- Investir na qualidade das ILPI. Só 280 delas são publicas no país. A maioria dos municípios brasileiros não possuem ILPI's para oferecer aos que delas necessitam (SECRETÁRIA DE DIREITOS HUMANOS DA PRESIDÊNCIA DA REPÚBLICA, 2014);

- Incentivar outras formas de apoiar as famílias com equipamentos sociais como Centros de Convivência, Centros-Dia, Residências Coletivas e Serviços de Apoio aos Cuidadores Familiares (MANUAL DE ENFRENTAMENTO À VIOLÊNCIA CONTRA A PESSOA IDOSA, 2014, p.71);

- Investimento em uma cidade segura, com ruas e calçadas sem buracos; iluminação nas ruas que ajude a enxergar melhor; equipamentos públicos para exercícios físicos que sejam compatíveis;

- Maior tempo dos semáforos para os pedestres, facilitando assim a travessia das pessoas idosas;

- Transportes públicos mais seguros;

- Levar em conta as necessidades da pessoa idosa de baixa renda. Como se verifica nos conjuntos habitacionais para a população menos favorecida, onde muitas vezes não se encontra corrimão nas escadas, muito menos conta com a presença de elevador.

- É preciso formar gerontólogos que tenham visão interdisciplinar, abrangente e humanística, mas também habilidades técnicas especificas para atuar com a pessoa idosa, sua família e seu ambiente, evitando violências de todos os tipos, particularmente as negligencias (MANUAL DE ENFRENTAMENTO À VIOLÊNCIA CONTRA A PESSOA IDOSA, 2014, p. 79).

$E$, acima de tudo, dar voz aos idosos, exigindo que a sociedade os ouça quanto as suas necessidades e anseios. Não devemos permitir que a pessoa idosa sempre ceda sua voz a outros, já que não há ninguém melhor que eles próprios para expressar suas realidades.

Convém, diante disto, lembrar as sábias palavras de Simone de Beauvoir no seu famoso livro "A Velhice" (1970):

Paremos de trapacear; o sentido de nossa vida está em questão do futuro que nos espera; não sabemos quem somos, se ignorarmos quem seremos: aquele velho, aquela velha, reconheçamo-nos neles. Isto é necessário, se quisermos assumir em sua totalidade nossa condição humana. Para começar, não aceitaremos mais com indiferença a infelicidade da idade avançada, mas sentiremos que é algo que nos diz respeito. Somos nós os interessados. Essa infelicidade denuncia contundentemente o sistema de exploração no qual vivemos. 


\section{REFERÊNCIAS}

AGÊNCIA NACIONAL DE VIGILÂNCIA SANITÁRIA. Resolução da Diretoria Colegiada, RDC n 283, 26 de setembro de 2005.

BERZINS, M.V. Violência institucional contra a pessoa idosa: a contradição de quem cuida. São Paulo: USP, 2009.

BRASIL. Ministério da Saúde. Caderno de Atenção Básica Envelhecimento e Saúde da Pessoa Idosa. Brasília: Ministério da Saúde, 2006.

ESTATUTO DO IDOSO, 2003.

MENEZES, M.R. Da violência revelada à violência silenciada. Ribeirão Preto: USP, 1999.

ORGANIZAÇÃO MUNDIAL DA SAÚDE. Missing voices: views o folder persons on elder abuse. Geneva: WHO/INPEA, 2002.

SECRETARIA DE DIREITOS HUMANOS DA PRESIDÊNCIA DA REPÚBLICA. Estatuto do Idoso dignidade humana como foco, Brasília, 2013.

SECRETARIA DE DIREITOS HUMANOS DA PRESIDÊNCIA DA REPÚBLICA. Manual de enfrentamento à violência contra a Pessoa Idosa - É possível prevenir, é necessário superar, Brasília, 2014.

WWW.ATERCEITAIDADE.NET/DIREITO-DO-IDOSO/. 